\title{
A natureza coletiva do processo de desenvolvimento de produto na indústria de roupas de malha
}

\author{
Beany Monteiro D.Sc. \\ beany@pep.ufrj.br \\ Francisco Duarte D.Sc. \\ duarte@pep.ufrj.br \\ Programa de Engenharia de Produção - COPPE/UFRJ \\ Área de Engenharia do Produto e Gerência da Produção \\ Caixa Postal 68507 CEP 21945-970 \\ Rio de Janeiro - RJ \\ Marçal Jackson \\ marcal@fundacentro.sc.gov.br \\ Diretor Técnico da Fundacentro /SC \\ Rua Silva Jardim, 213. Prainha, Centro \\ CEP 88020-200 \\ Florianópolis - SC
}

Este artigo é uma contribuição para compreender o processo de desenvolvimento de produtos na indústria de roupa de malha enfatizando a sua dimensão coletiva. Descreve-se tal processo via os objetos intermediários de concepção (desenhos, moldes, peças-piloto e modelagens) e são identificados os atores de projeto, desenvolvimento e produção da roupa, numa planta de confecção de moda em malha no Rio de Janeiro. Evidencia-se que este é um processo social, mediado pelos objetos de concepção. Demonstra-se que a modelista faz a mediação entre a criação e a produção das roupas e que a peça-piloto, fabricada no início desse processo, é central para o desenvolvimento desse produto.

Palavras-chave: projeto de produto; objetos intermediários de concepção; malharia

This article is a contribution towards an understanding of product development in the knitwear industry. The process is described via intermediate conceptual objects (drafts, moulds, pilot work pieces and models) and the project players are identified along with the development of product clothing in a factory for knitwear in Rio de Janeiro. It is shown that conceptual objects are inserted in a social process. It is shown that designer acts as an intermediary between the creation and the production of clothing and that the pilot work piece, which is made at the beginning of the process, is central to product development.

Keywords: design; in-between objects; knitwear.

\section{Introdução}

Procuramos compreender o processo de desenvolvimento de roupas de malha focando sobre a sua natureza coletiva. A partir do conceito de objetos intermediários de concepção verificamos que as interações entre os diferentes atores estão no centro desse processo. Diferentes objetos, como desenhos, moldes, modelagens no CAD - Computer Aided Design - e principalmente a peça-piloto - um protótipo do futuro produto - são suportes dessas interações e permitem a traçabilidade do desenvolvimento do produto. A função do CAD, no início desse desenvolvimento, está restrita à simulação do custo da malha. Um estudo de campo realizado numa confecção de roupa de malha no Brasil coloca em evidência a centralidade da peça-piloto para o uso do CAD no início do processo e como suporte das interações entre os atores do projeto e da produção de roupas de malha. O estudo descreve o papel da modelista, um dos atores desse processo, como uma papel de tradução e de interpretação do projeto e da produção. 
No Processo de Desenvolvimento de Produto - PDP - confrontam-se competências ligadas às tendências de moda, comércio e produção. Essa confrontação é central para o bom desempenho das empresas de vestuário que procuram a redução do tempo de desenvolvimento de produto, com a diversificação de modelos e com a racionalização dos recursos materiais oferecer produtos competitivos e adequados aos seus diferentes clientes.

O uso do CAD - Computer Aided Design - dá agilidade ao PDP em função de reutilização dos arquivos gravados durante o desenvolvimento de novos modelos, da economia de recursos materiais e do aumento da produtividade. No entanto, no caso da confecção de roupas de malha estudada, o uso do CAD não substitui os objetos de concepção tradicionalmente utilizados nesse processo, tais como os moldes e a peça-piloto. A utilização do CAD no início do PDP é importante para testar a viabilidade industrial e comercial do modelo a ser desenvolvido.

Temos como objetivos específicos:

- descrever o PDP via os objetos intermediários de concepção da roupa (desenhos, moldes, peçapiloto e modelagem). O PDP coloca em cena atores e competências que interagem em torno de diferentes objetos de concepção da roupa. Esses objetos fazem a mediação entre a concepção, a produção e o uso da roupa.

- identificar os atores do projeto e da produção da roupa de malha (produto de baixo custo, desde o início do PDP) e suas interações. Esse é um processo social no qual o papel da modelista é traduzir os aspectos comerciais do produto numa modelagem industrial.

- situar o uso do CAD no PDP, tendo em vista a reutilização, a cópia e a atualização de modelos, para ganhar tempo e poupar recursos nesse processo. A principal função do CAD no início do PDP é simular o custo do modelo reutilizando as modelagens anteriores de produtos similares e, no final do processo, planejar o corte do tecido (risco).

Nosso marco referencial teórico está apoiado nos estudos que tratam o PDP do ponto de vista de sua natureza coletiva (BUCCIARELLI, 1996; JACKSON, 1998) e nos estudos que descrevem esse processo tendo como foco os objetos intermediários de concepção e a comunicação na equipe de projeto (MER et al., 1995; ECKERT, 1997). Procuramos, a partir desse referencial, considerar a interação entre os atores do projeto da perspectiva que os objetos realizam nessas interações e mais especificamente procuramos qualificar essas mediações de acordo com o tipo de objeto e a sua característica nas interações.

\section{O PDP: Um processo social}

De acordo com Bucciarelli (1996) o projeto é um processo social, que envolve não só a participação de diferentes atores, mas a interação destes em torno de diferentes objetos que serão transformados num mundo comum aos diferentes atores. Uma vez que diferentes atores tratam de diferentes partes do objeto de concepção, o processo de projeto depende das interações e das negociações entre os atores para encontrar um compromisso comum.

A incerteza é uma característica intrínseca da atividade de projeto e não pode ser eliminada por um planejamento meticuloso das tarefas de concepção. Por isso, Bucciarelli (1996) refere-se à negociação e às interações entre os atores como necessárias para que as decisões tomadas na etapa de concepção sejam coerentes com as situações futuras ou pelo menos o mais próximo delas.

Nesse sentido Jackson (1998) define o projeto como um processo de gestão e de deliberação que remete à interação e à construção social durante o seu desenvolvimento. Olhar o objeto de concepção independentemente das relações entre os atores do projeto é inútil do ponto de vista desta construção social. O autor mostra que uma modelização mais rica do processo de projeto e uma construção de condições apropriadas para transformar as representações dos atores do projeto são critérios mais importantes para o projeto do que a aplicação de métodos específicos a cada etapa do processo de concepção.

Na perspectiva de Jackson (1998) a concepção é uma heurística coletiva guiada por um projeto, representada na Figura 1 como o espaço de discussão e negociação entre o desejado e o possível. A estruturação do projeto, considerando os desafios sociais que o envolve, exige regulações e reajustes permanentes entre os atores da equipe. O resultado é tanto mais adequado quanto mais existirem espaços de discussão próprios à equipe de projeto (Figura 1). 


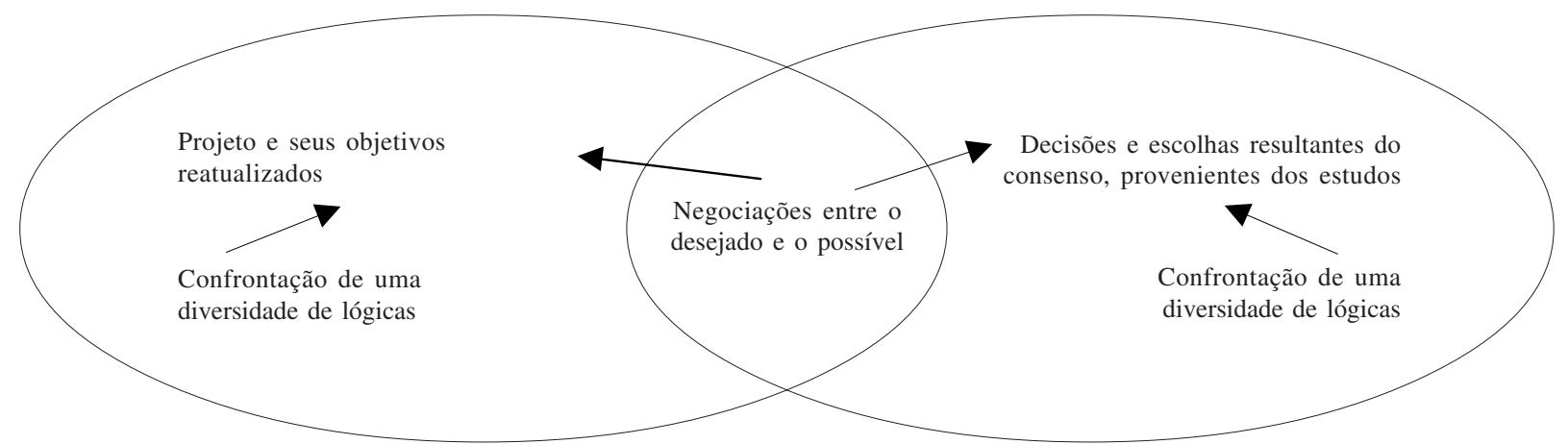

Figura 1: O processo de concepção compreendido como uma heurística coletiva guiada por um projeto (JACKSON, 1998)

Bucciarelli (2002) refere-se ao modo de harmonização entre diferentes intenções e propostas durante o curso do design. Essa questão de caráter filosófico colocada por um engenheiro tem como objetivo, segundo o autor, explorar a possibilidade de ampliar o problema geral da engenharia (projeto e

implementação de artefatos mecânicos) para ver como esses artefatos servem para construir uma ponte entre pensamento e objeto. A natureza coletiva do projeto e do Processo de Desenvolvimento de Produto - PDP chama a atenção das escolas de administração, voltadas para o aspecto da gestão do processo, enquanto nos departamentos de engenharia focamos nos problemas individuais para resolver problemas de natureza instrumental.

Em torno do conceito de mundo objeto (object world), que representa uma variedade de objetos particulares e modos particulares de representação, o objeto tem seu próprio instrumento, texto, referências, protótipos, ferramentas, catálogos. Ou seja, o objeto define uma ontologia, um escopo particular dentro do qual o problema geral se especifica.

Bucciarelli (2002) descreve o objeto mundo como um artefato, um elemento de linguagem que define e descreve propriedades do produto final mas que tem nesse elemento um objeto de negociação e de deliberação que pode assumir diferentes formas nas discussões entre os atores. Nesse sentido através da construção e uso dos artefatos os atores ampliam suas competências de interação. A construção e a manipulação dos artefatos geram idéias e pensamentos consistentes para suas análises e validações dos mundos objetos. Os artefatos possuem uma função essencial de tornar as negociações possíveis entre os atores que têm interesses e responsabilidades distintas. Ou seja, os artefatos permitem socializar os objetos mundo que, pela sua característica particular, de uma disciplina específica, torna o diálogo e a relação com uma outra disciplina muitas vezes sem uma interface comum. Essas diferentes disciplinas integram-se no processo de design compondo uma troca com esse processo: elas são ao mesmo tempo elemento e função do artefato. Isto é, através dos artefatos, como elementos de comunicação, designers relacionam pensamento e objeto, função e estrutura. Entre pensamento e objeto uma linguagem geral é construída e permite o diálogo (SCHÖN, 1983; BUCCIARELLI, 1996).

\section{Os objetos intermediários de concepção}

O método dos objetos intermediários de concepção vem sendo desenvolvido e utilizado, desde o início da década de 90, pelos pesquisadores do laboratório CRISTO (Centre de Recherche: Innovation SocioTechnique et Organisation Industrielle), da Université Pierre Mendès-France, "em parceria com outros laboratórios como o $3 S$ (Sol-Solides-Structure) da École Nationale Supérieur d'Hidraulique et de Mécanique de Grenoble e SEE (Sócio-Économie Environnement et Développement) da Foundation Universitaire Luxembourgeoise" (CAMPOS, 2002, p. 47).

A base desse conceito é o fato de ser a atividade de projeto mediada pelos objetos de concepção. Outra é o fato de ser o projeto um processo social, no qual cada ator representa um papel como ator social (BUCCIARELLI, 1996). Para agir esses atores concebem e utilizam objetos que permitem tomar decisões, interagir com o outro e expressar as intenções da ação. Tais objetos são suportes para a ação, que podem ser um resultado do trabalho; neste caso, são compreendidos como mediadores entre atividades diferentes ou como mensageiros, no decorrer do trabalho, da idéia que se quer transmitir. Em ambos casos, sejam mensageiros ou mediadores, os "objetos intermediários de concepção" permitem descrever o processo de desenvolvimento de um produto, referenciando-o às diferentes ações.

Segundo Mer et al. (1995) os objetos são vetores de coordenação entre diferentes atores e estão no centro de suas interações. $\mathrm{O}$ objeto permite introduzir diferentes eixos para caracterizar a sua interação no processo 
de concepção. "Um objeto mensageiro é um objeto transparente que somente transmite uma intenção, uma idéia. Ele não modifica em nada a idéia ou a intenção de seu produtor. Ao contrário, o objeto mediador modifica a idéia, a intenção inicial, pela sua existência e sua utilização como suporte de transmissão" (CAMPOS, 2002, p. 50).

Uma segunda categorização coloca o objeto como aberto e fechado. O objeto aberto incita um trabalho de interpretação enquanto o objeto fechado transmite uma prescrição. O objeto deve revelar-se um modelo de referência compartilhado: o modelo sobre o qual se apóia o objeto influencia as coordenações, das quais ele é o vetor. "O objeto aberto encoraja o trabalho de interpretação ao passo que o objeto fechado transmite uma prescrição... a noção de abertura está ligada a uma margem de manobra para que o usuário o modifique... ao contrário um objeto fechado diminui e tende a fazer desaparecer essa margem" (ibidem).

Uma das mais importantes contribuições dos objetos intermediários para analisar as situações de projeto é permitir uma descrição dinâmica do PDP. Os objetos estão no centro das interações entre os atores e são, simultaneamente, reflexos das diferentes ações. Como atores do processo os objetos desempenham o papel de mediadores na interação ator-ator. Como testemunhas eles são uma referência da interação entre o ator e o objeto (Figura 2). ção" e o "desenvolvimento". A primeira constitui-se pelas principais características do pedido e é marcada pela incerteza. A segunda consiste em fornecer uma série de protótipos para ensaiar a realização do produto.

Ocorre entre essas fases uma mudança de linguagem como a tradução não literal de um texto. A passagem, de um registro estabelecido em termos funcionais (com o cliente, o pedido) para um registro do tipo sintético (que representa o mesmo pedido para os especialistas que vão executá-lo) é uma primeira aproximação do que consiste a tradução. Com a mudança de linguagem mudam as regras e as convenções internas que instrumentalizam e suportam as definições: funcionalidade de um lado e simulação do comportamento das funções, do outro.

Schön (1983) ressalta o papel dos desenhos como reflexos de uma conversação dos projetistas com a situação. A partir de um estudo realizado na indústria de malharia em alguns países da Europa, Eckert (1997) mostra que melhorar a comunicação na equipe de projeto passa pela análise da comunicação baseada num desenho (sketch): “Knitwear designers communicate their designs to knitting machine technicians with a 'technical sketch' comprising a short verbal description, a set of measurements and a sketch. (...) In theory the sketch should clarify the specification. However the technicians, who do a lot of detail design in the course of creating knitting

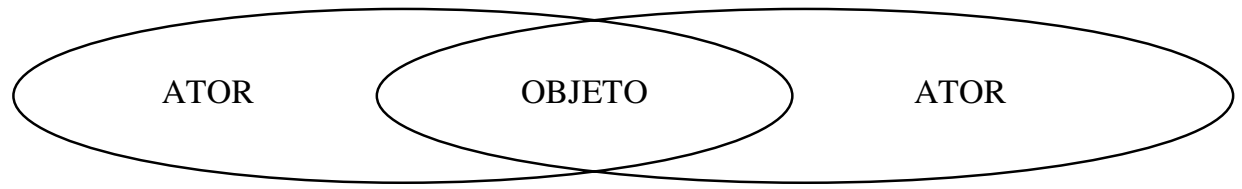

Figura 2: Representação do processo de concepção (CAMPOS, 2002)

A representação elaborada por Campos (2002) ressalta o caráter mediador dos objetos de concepção não só entre ator-objeto do processo mas entre diferentes atores, como fornecedores e consumidores: "( a)s diferentes visões são conciliadas na construção dos objetos mas deve-se destacar ainda que não se trata de uma síntese dos diferentes interesses mas de uma sobreposição, ou seja, as diferenças nem sempre são desfeitas" (CAMPOS, op.cit.).

Segundo Jeantet (1998) a interação entre esses atores remete ao papel do objeto intermediário como vetor da comunicação no projeto. $\mathrm{O}$ autor chama a atenção sobre a coerência entre o nível de representação do produto e a forma de coordenação. Para passar da idéia de um produto à sua realização, são necessárias etapas intermediárias, que se configuram a partir de duas grandes fases: a "pré-concep- machine programs based on these specifications, tend to ignore the sketches and rely mainly on the verbal descriptions, which only give broad indications of categories" (STACEY, ECKERT e McFADZEAN, 1999, 04, pp. 1-6).

As fontes de inspiração dão significado e reputam a devida importância a essas conversações nas fases iniciais do processo de desenvolvimento de produto, que são, em geral, pouco valorizadas nos estudos sobre confecção de roupas de moda em malha. Para essa autora, o uso das fontes de inspiração é vital para a performance do projeto, no que diz respeito ao desenvolvimento da malharia, mas depende de estratégias que o apóie. Esse uso varia, ainda, de acordo com a moda e a estrutura das competências dos projetistas. A pesquisa das fontes de inspiração é descrita pela autora a partir dos seguintes itens: 
- contexto da tendência de moda da estação: olhando primeiramente para outras roupas ou fotos de roupas, os estilistas estudam os espaços possíveis de projeto. Uma compreensão intuitiva destes espaços é uma das mais importantes competências dos estilistas;

- ilustração dos conceitos: as características do projeto são comunicadas em termos de painéis, com fotos, amostras e desenhos de roupas. A forma concreta da roupa é, em geral, especificada com referência a outra roupa;

- fontes das características do projeto: pelo estudo de outras roupas, os estilistas apreendem as principais características, como acabamentos e bolsos. Isto define um contexto, em termos de proporção e estilo. Eles podem ser diretamente aplicados no projeto;

- esquemas de cor: fotos ou amostras com as cores da estação compõem a cartela de cores da coleção;

- coordenação da coleção: motivos, estruturas e cores formam um quadro no qual são reunidos os desenhos, numa coleção coordenada por um tema.

Além disso, os estilistas referem-se às fontes de inspiração, tal como uma peça de arte, um filme, um ator, para comunicar suas idéias e suas intenções. A subestimação da importância das fontes de inspira-

\section{$4 \mathrm{O}$ estudo de caso}

Esse estudo de caso, feito a partir de um estudo de casos múltiplos (YIN, 2001), compreendeu uma etapa inicial de identificação e formulação de uma problemática comum a diferentes empresas do setor de vestuário no Rio de Janeiro; uma etapa intermediária de visitas e acompanhamentos em algumas dessas empresas; e uma etapa final na qual realizou-se o estudo de caso em uma empresa de confecção de roupas de malha. $\mathrm{O}$ estudo teve como objetivos principais compreender o PDP, identificar os atores e objetos e situar o uso do CAD no processo.

A empresa pesquisada pertence a um grande grupo brasileiro que produz a malha, confecciona a roupa e comercializa seus produtos por todo o Brasil. O total de pessoas na planta de confecção do Rio de Janeiro no primeiro semestre de 2003 era de 170 pessoas, sendo 120 na costura, 24 no corte e 11 no setor de desenvolvimento de produto sendo, portanto, uma empresa de médio porte que atua num forte contexto competitivo, como podemos ver na Tabela 1 .

O contexto de grande diversificação de modelos indicou a elaboração da peça-piloto e a atividade da modelista como referenciais centrais para compreender o processo de desenvolvimento de produto nessa empresa. Essa peça é um objeto intermediário de concepção da roupa central para a interação entre os diferentes atores desse

Tabela 1: Distribuição das empresas de confecção brasileiras por porte (Adaptado de IEMI,1999).

\begin{tabular}{lcccc}
\hline Porte & Indústrias & $\begin{array}{c}\text { Participação } \\
(\boldsymbol{\%})\end{array}$ & $\begin{array}{c}\text { Produção } \\
\text { (peças) }\end{array}$ & $\begin{array}{c}\text { Participação } \\
(\boldsymbol{\%})\end{array}$ \\
\hline Pequeno & 1.2317 & 71 & 966.266 & 11,4 \\
\hline Médio & 4.630 & 26,5 & 4.140 .923 & 48,8 \\
\hline Grande & 431 & 2,5 & 3.149 .388 & 39,8 \\
\hline Total & 17.378 & 100 & 8.256 .577 & 100 \\
\hline
\end{tabular}

ção para o projeto de produto desvaloriza a pesquisa dos projetistas e prejudica a criatividade. Dando aos projetistas um suporte efetivo para as suas pesquisas, eles podem ser muito produtivos e o uso das fontes de inspiração ser reconhecido, segundo o estudo de Eckert (1997). processo até a costura da roupa. Em 2002/2003, quando foi feito o estudo, eram desenvolvidos cerca de 25 novos modelos a cada semana, portanto eram fabricadas 25 peças-piloto, sendo cortadas por dia em torno de 14 mil (na produção), na planta estudada situada em Duque de Caxias, RJ (Tabela 2).

Tabela 2: Peças-piloto e volume de produção entre 1992 e 2002 (MONTEIRO, 2004).

\begin{tabular}{cccc}
\hline Ano & $\begin{array}{c}\text { Peças Piloto/ } \\
\text { semana }\end{array}$ & Efetivo no corte & $\begin{array}{c}\text { Volume de produção } \\
\text { no corte }\end{array}$ \\
\hline 1992 & 3 & 36 & $4 \mathrm{mil} \mathrm{peças/dia}$ \\
\hline 1999 & 10 & 12 & $20 \mathrm{mil} \mathrm{peças/dia}$ \\
\hline 2002 & 25 & 24 & $14 \mathrm{mil} \mathrm{peças/dia}$ \\
\hline
\end{tabular}


Houve um aumento no número de peças-piloto fabricadas e, portanto, do trabalho no setor de desenvolvimento de produto. A direção industrial da empresa tinha interesse em identificar elementos que pudessem ser reutilizados visando dar maior agilidade do PDP em virtude do aumento do número de modelos desenvolvidos e da redução do volume produzido.

\section{Metodologia}

O estudo de caso foi realizado em três fases principais: uma fase inicial de apresentação da pesquisa de tese, uma fase intermediária de entrevistas dirigidas ao pessoal de desenvolvimento de produto e uma fase final de observações em situações características do PDP. Os procedimentos metodológicos utilizados no estudo foram:

- entrevistas com o diretor industrial; o gerente de produção e o gerente de Recursos Humanos das 12 empresas visitadas;

- entrevistas e observações não estruturadas com os diferentes atores sociais do projeto (Processo de Desenvolvimento de Produto - PDP) e da produção (corte, costura e Planejamento e Controle de Produção - PCP);

- elaboração e aplicação de instrumentos para a coleta de dados: planilha de observação, gravação de diálogos e interações, fotografias das situações e objetos de projeto;

- acompanhamento sistemático do trabalho realizado no setor de desenvolvimento de produto nas três empresas: ternos, camisas e roupas de malha;

- aprofundamento da pesquisa centrado na atividade da modelista e na sua interação com a estilista e a riscadeira cadista na empresa de roupas de malha;

- análise e interpretação dos dados obtidos nas etapas anteriores.

As situações analisadas referem-se (i) ao desenvolvimento de um modelo (o painel de formas, os moldes de fabricação e a confecção da peça-piloto); (ii) à simulação do custo da peça-piloto (a reutilização dos moldes gravados no $\mathrm{CAD}$ ) e (iii) à modelagem industrial (graduação de tamanhos e introdução dos moldes no CAD). A identificação dessas situações foi feita a partir das entrevistas e observações com os diferentes atores do PDP.

\section{Resultados: O PDP - Seus ato- res e objetos intermediários}

A estratégia de diversificação de modelos, tendo em vista a redução do volume de produção, diminui o tempo de especificação do modelo e aumenta o número de peças-piloto fabricadas. O modelo é vendido a partir dessa peça. Ela orienta o processo de desenvolvimento de produto e é um objeto mediador entre o projeto e a produção da roupa, fabricado pelo coletivo de trabalho, nas etapas iniciais do PDP. É a partir dessa peça que o CAD é utilizado para simulação do gasto da malha na etapa inicial do PDP. Para essa simulação são reutilizadas as modelagens de modelos anteriores, feitas pela modelista, e introduzidas no CAD para o planejamento do corte desses modelos. É portanto a partir da peça-piloto que podemos observar a reutilização dos objetos de projeto, como as modelagens.

Os principais atores desse processo e seus respectivos papéis são:

1. A estilista que faz a pesquisa de moda e o desenho do modelo referindo-se a estes objetos quando interage com a modelista.

2. A modelista que faz a modelagem e antecipa o processo de fabricação procurando mostrar para a estilista as adaptações que devem ser feitas no desenho para alcançar a produção e um acabamento desejados.

3. A costureira que confecciona a peça-piloto de acordo com o desenho segundo as orientações da modelista.

4. A riscadeira que usa o CAD e faz o planejamento do corte e o cálculo do consumo da malha no corte, utilizando como referências as malhas e os moldes.

Diferentemente de outros processos de desenvolvimento de produto a interação entre esses atores é assimétrica e revela diferentes níveis sociais e culturais. A estilista possui uma formação equivalente à pós-graduação enquanto a modelista possui o curso fundamental. Isso gera algumas dificuldades nas interações o que acentua ainda mais o papel central dos objetos nessas interações.

O PDP e seus objetos intermediários foram sintetizados como o esquema abaixo no qual procuramos identificar em cada etapa o objeto correspondente bem como a passagem entre um e outro (Figura 3 ). 


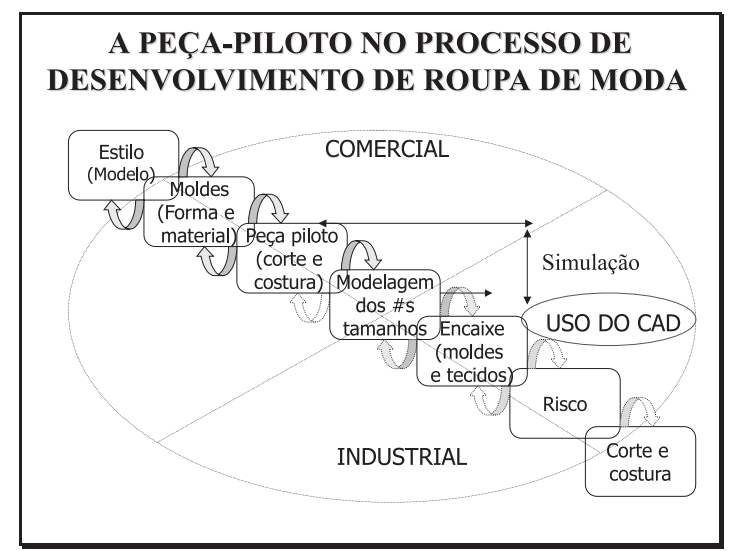

Figura 3: As etapas do PDP e os objetos intermediários

Nesse processo a peça-piloto é a base para a tomada de decisões no PDP. Assim como foi descrito por Campos (2002) sobre a lista de especificações no caso do desenvolvimento de produtos no setor automotivo, "com ela é possível determinar o custo de matéria-prima, estimando o preço de venda que é repassado ao representante de vendas para iniciá-las antes mesmo da fabricação industrial".

Quanto ao CAD a empresa possui duas estações de trabalho sendo uma gráfica e outra para procedimentos de cópia e introdução de moldes. O sistema operacional é dedicado e na versão atual os programas gráficos estão implantados numa plataforma que não possui interfaces do tipo janela (windows). $\mathrm{O}$ CAD implantado é da empresa "Investrônica do Brasil”. A versão da empresa foi atualizada em 1999.

O computador é utilizado no PDP para otimizar o corte visando a economia de matéria-prima. Entretanto, para que o produto seja vendido é preciso proceder ao cálculo do custo do modelo em desenvolvimento. Esse cálculo é feito com o apoio do CAD tendo como referências a peça-piloto desse modelo e os moldes de modelos similares gravados no CAD. Após a introdução das modelagens no CAD, elas são relacionadas à grade de tamanhos e à malha na qual serão cortadas. As modelagens são introduzidas no CAD através de uma mesa, denominada mesa de digitalização. $\mathrm{O}$ Processo de Desenvolvimento de Produto -PDP- tem início com a pesquisa de moda em revistas e feiras especializadas. Essa pesquisa é sintetizada em painéis que orientam o desenvolvimento dos modelos. $\mathrm{O}$ desenho desses modelos é a etapa seguinte à pesquisa de moda. Esses desenhos estão relacionados a uma cartela de cores e de tecidos. A partir do estudo do desenho, feito pela estilista a modelista faz os moldes que são recortados no papel e servem como gabaritos para o corte da malha. Esses moldes cortados no pano são encaminhados para a costureira pilotista que irá executar a peça-piloto (Figura 4).

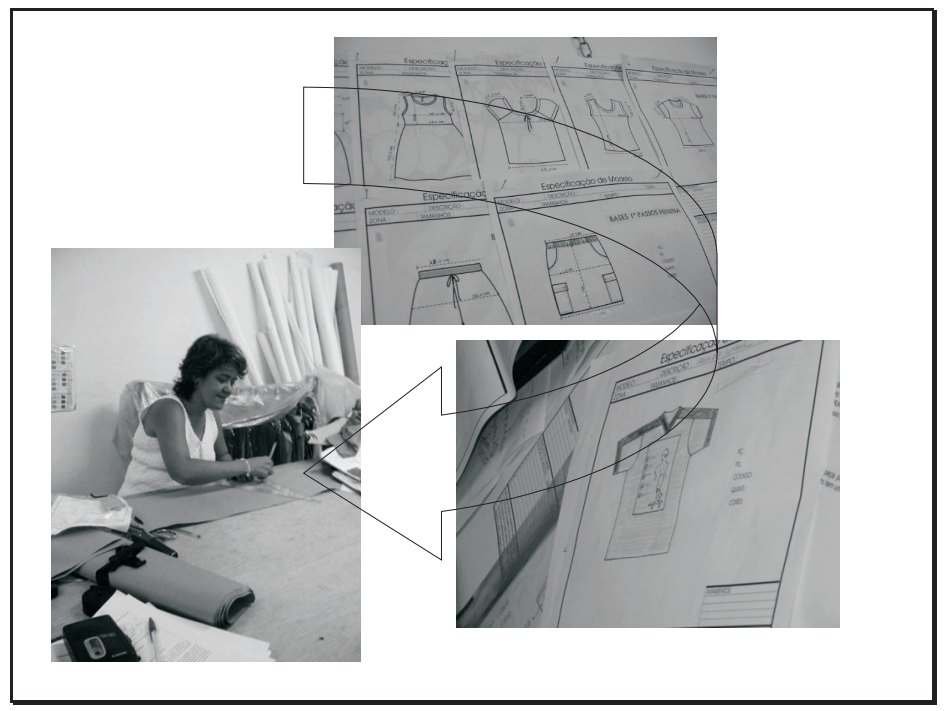

Figura 4: A etapa inicial do PDP e seus objetos 
Para execução dos moldes a matéria-prima é analisada (principalmente a elasticidade da malha) e as medidas do modelo similar são adaptadas a essa matéria-prima. Esses ajustes são anotados no próprio molde e serão aprovados ou não conforme a avaliação da peça depois de costurada. O desenho é encaminhado junto com os moldes para as costureiras pilotistas e algumas orientações sobre a cor da linha, a ordem de prioridade, os recursos de costura, tais como o tipo de ponto e ajuste da máquina são transmitidas. $\mathrm{O}$ resultado da atividade da costureira é uma peça-piloto do modelo em desenvolvimento. Aprovada a peçapiloto ela é entregue para a riscadeira cadista que irá proceder ao cálculo do custo. $\mathrm{O}$ esse cálculo é feito utilizando as modelagens de modelos similares introduzidas no CAD (Figura 5).

Em algumas situações foi observado que a modelagem é modificada diretamente no CAD, em função de incompatibilidades entre o custo previsto no momento do cálculo da peça-piloto e de variações nas caracterís- ticas da malha. Duas situações típicas foram observadas: o corte nas costas da blusa ("costa emendada") e o corte na lateral de um short cujo modelo original vendido não tinha costura. Na primeira foi realizado o cálculo da peça-piloto desse modelo. Na segunda foi introduzida uma costura lateral numa bermuda cujo modelo tinha sido desenhado com uma costura única nas entre-pernas. Essas alterações no modelo depois da emissão da ordem de corte é uma demonstração da não linearidade desse processo. As modificações são feitas tanto pela modelista quanto pelas riscadeiras diretamente no CAD.

A análise desse processo via os seus objetos intermediários permite discutir a transição entre o projeto e a produção tendo como objeto a peça-piloto. Esse objeto realiza uma mediação entre o desenho e a modelagem, representada na Figura 6.

A atividade da modelista tem um caráter mediador que gera objetos de diferentes naturezas: objetos abertos

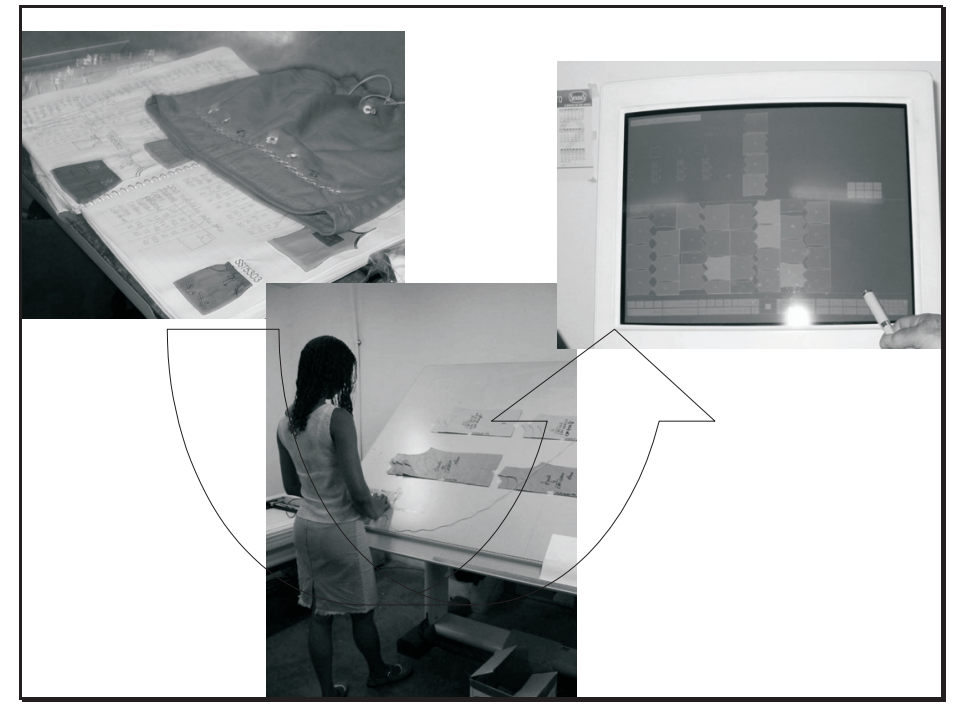

Figura 5: A etapa intermediária do PDP e seus objetos

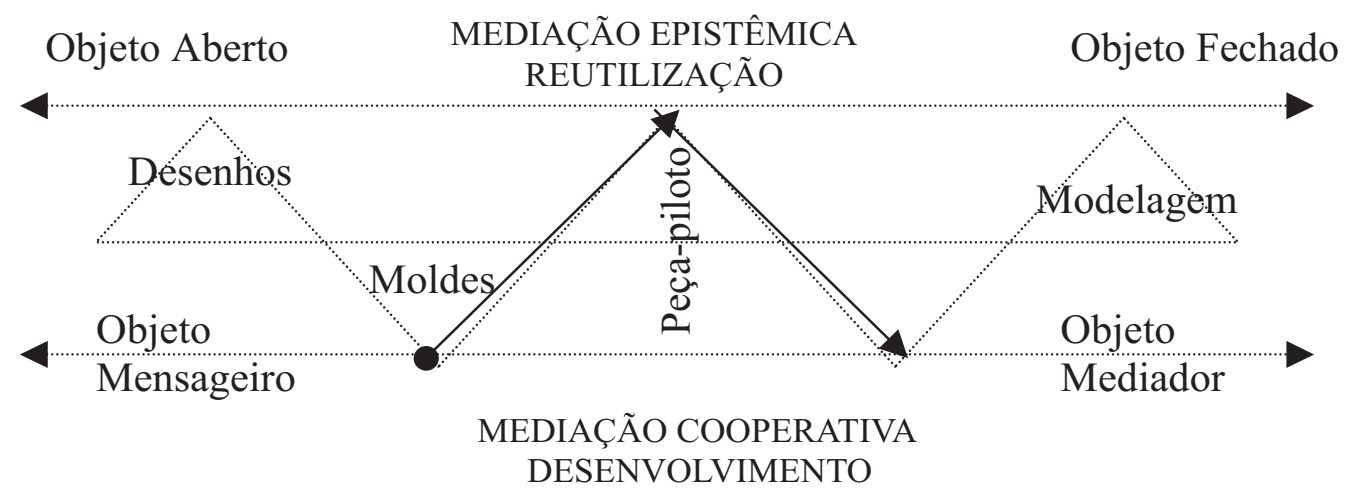

Figura 6: Classificação dos objetos no PDP a partir da análise da atividade da modelista 
voltados para a fabricação de uma peça, tais como os moldes da peça-piloto, e objetos fechados, voltados para a produção industrial, tais como as modelagens. Duas situações permitem ilustrar essa afirmação:

\section{Confirmação da cor do chuleado}

Devido ao grande número de modelos em desenvolvimento no período em estudo não havia sido possível estampar uma peça-piloto de um modelo para o qual estava prevista uma estampa. Como a malha era preta e a estampa prata a chefe de costura, ao receber o lote de produção já cortado, vai confirmar se o chuleado, que é uma costura de acabamento da peça, era para combinar com a malha (preta) ou com a estampa (prata). A modelista então encaminha a costureira para a estilista uma vez que essa especificação fazia parte da estética do modelo e não havia sido definida na ficha técnica. Esta ficha acompanha o modelo durante toda a produção. A costureira trazia consigo a ficha e o lote de peças cortadas. Ela fez referência ao desenho, no qual não constava a indicação da cor do chuleado e que portanto deveria ser definida.

\section{Cópia de uma roupa pronta}

Nessa situação de cópia de um modelo a partir de uma roupa pronta não havia desenho nem uma ficha técnica inicial. A principal dificuldade para a modelista era compreender as soluções dadas à modelagem considerando que esta não estava disponível e a roupa já havia passado por um processo industrial: "aqui, se a gente pega um lote produzido e compara uma peça com a outra vai ver que tem diferença. $\mathrm{Na}$ modelagem, cada um tem um jeito de trabalhar e eu não sei porque essa roupa foi feita assim" (T., a modelista). Depois de ser tirado o molde e fabricada a peça-piloto as roupas foram comparadas pela estilista mais nova da empresa e assim sucessivamente até encontrar duas peças exatamente iguais. Os moldes então foram graduados e os diferentes tamanhos não precisaram mais ser comparados uma vez que a base já havia sido aprovada. Uma observação da modelista sobre as roupas compradas era que estas tinham uma modelagem muito estreita, com pescoço e punho muito justos mas que isso, provavelmente, havia sido "comido" na costura. Uma outra questão observada era que a cópia impedia a criação do molde a partir das bases desenvolvidas pela modelista. A cópia é um fator de estresse para a atividade dessa modelista.

O acompanhamento e a análise dessas situações permitiu caracterizar a atividade da modelista como uma reflexão sobre a produção. A modelista realiza uma tradução do projeto (forma, função, material) para a produção (corte e costura). Essa tradução foi identificada em dois momentos principais. O primeiro de interpretação do desenho, no qual a modelista recorria ao seu caderno para identificar o modelo similar já desenvolvido. O segundo de tradução no qual a peça-piloto fabricada em um único tamanho e uma única vez deveria ser transformada numa modelagem para ser produzida em escala industrial.

\section{Conclusão}

Para compreender o Processo de Desenvolvimento de Produto -PDP- no setor de confecção de roupas de moda realizou-se um estudo de caso no setor de desenvolvimento de produto de uma empresa de confecção de roupas de malha em Duque de Caxias, no Rio de Janeiro. Nesse estudo observou-se que, entre a concepção, a produção e a comercialização da roupa, é fabricada uma peça-piloto em torno da qual interagem esses diferentes atores do PDP.

Anterior ao uso do CAD, que dá agilidade ao processo otimizando o gasto de tecido no corte, a fabricação dessa peça possibilita a simulação do gasto de matéria-prima no CAD nas etapas iniciais desse processo. Para simular o custo da peça-piloto, e validar ou não a sua produção industrial, as modelagens gravadas no computador são reutilizadas no contexto de desenvolvimento do novo produto. Essa reutilização tem como fonte de inspiração, ou referências, a peça-piloto e o dicionário de modelos.

O PDP constitui-se por três etapas principais: uma etapa inicial de concepção do modelo (desenho e moldes); uma etapa intermediária de elaboração da peça-piloto e uma etapa final de passagem do produto para a produção. Nesse processo a modelista faz a mediação entre a etapa inicial de concepção do modelo, na qual ela atua interpretando o desenho e fazendo os moldes para a fabricação da peça-piloto, e a etapa final de passagem do modelo para a produção, quando, a partir da peça-piloto fabricada é feita a modelagem industrial da roupa.

A partir do acompanhamento da atividade da modelista cada uma dessas etapas foi analisada segundo seus objetos atores e atividades. A análise do PDP via as interações entre os atores teve como principal resultado identificar a inter-relação entre os diferentes objetos intermediários de concepção do produto nesse processo. No presente estudo essa inter-relação tem como objeto central a peça-piloto. Essa peça permite antecipar a produção industrial e o uso da roupa nas etapas inicias do PDP.

As análises realizadas nas situações identificadas como características desse processo mostraram que o uso do CAD é instruído pelos diferentes atores do Processo de Desenvolvimento de Produto -PDP- o que garante o desenvolvimento de soluções adequadas e criativas de projeto. É a Inteligência Natural e não a artificial que 
possibilita e garante a criatividade e a eficiência do processo (CROSS, 1999). Nesse sentido é a atividade da modelista que interpreta e traduz os requisitos comerciais e industriais do modelo tem um papel chave para o desenvolvimento de conhecimentos sobre o processo e para a adequação do modelo criado à fabricação.

\section{Referências}

BUCCIARELLI, L. L., Designing Engineers. Cambridge: The MIT Press, 1996.

BUCCIARELLI, L.L., "Between thought and object in engineering design”. Design Studies (23) pp. 219-231. Elsevier Science Ltd., Great Britain, 2002.

CAMPOS, N. A., Equipes multifuncionais de projeto: condições para um funcionamento eficiente. Tese de Mestrado, Escola de Engenharia da UFMG, 2002.

CROSS, N., "Intelligence in Design”. Design Studies, vol. 20, no. 1, pp. 25-39, January, 1999.

ECKERT, C. M., "Design inspiration and design performance". In: Proceedings of the $78^{\text {th }}$ World Conference of the Textile Institute. Thessaloniki, Greece: The Textile Institute, 1997, vol. 1, pp. 369-387.

JACKSON, M., Entre situations de gestions et situations de déliberations : l'action de l'ergonome dans le projets industriels. Doctorat en Ergonomie, Paris, CNAM, 1998.

JEANTET, S., "Les objets intermediaires dans la conception. Eléments pour une sociologie des processus de conception des produits". Sociologie du travail, 1998.
MER, S., TICHKIEWITCH, S., JEANTET, A. "Les objets intermédiaires de la conception: modélisation et communication". In: Jean CAELEN, Khaldoun ZREIK, Le communicationnel pour concevoir. Europia Productions, Paris, 1995.

MONTEIRO, B., "Projeto e Fabricação de Roupa de Moda em Malha Assistidos por Computador". Anais do $3^{\circ}$ Congresso Internacional de Ergonomia e Usabilidade, Design de Interfaces e Interação Humano-Computador. PUC - Rio / Rio de Janeiro, 2004 a .

MONTEIRO, B., A centralidade da peça-piloto no processo de desenvolvimento de roupas de malha: um estudo de caso. Tese de doutorado em Engenharia de Produção, COPPE/UFRJ, 2004.

RABARDEL, P., Les hommes et les technologies. Approche cognitive des instruments contemporaines. Armand Colin Editeur, Paris, 1995.

SCHÖN, D. A ., The reflective practitioner. Usa, Basic Books, Inc.: Cambridge, 1983

STACEY, M.; ECKERT, C.M.; McFADZEAN, J. Sketch Interpretation in Design Communication. In: Proceedings of the 12th International Conference on Engineering Design. Technical University of Munich, Munich, 1999, volume 2, pp. 923-928.

http://www.cse.dmu.ac.uk/ mstacey/pubs/sketchiced-a-.shtml

YIN, R. K., Estudo de caso. Planejamento e Métodos. Porto Alegre, Bookman, 2001.

Submetido em abril/2002

Aprovado em setembro/2004 